\title{
WestVirginiaUniversity
}

THE RESEARCH REPOSITORY @ WVU

Graduate Theses, Dissertations, and Problem Reports

2000

\section{Persistence of response variation and repetition}

\author{
Adam Howard Doughty \\ West Virginia University
}

Follow this and additional works at: https://researchrepository.wvu.edu/etd

\section{Recommended Citation}

Doughty, Adam Howard, "Persistence of response variation and repetition" (2000). Graduate Theses, Dissertations, and Problem Reports. 739.

https://researchrepository.wvu.edu/etd/739

This Thesis is protected by copyright and/or related rights. It has been brought to you by the The Research Repository @ WVU with permission from the rights-holder(s). You are free to use this Thesis in any way that is permitted by the copyright and related rights legislation that applies to your use. For other uses you must obtain permission from the rights-holder(s) directly, unless additional rights are indicated by a Creative Commons license in the record and/ or on the work itself. This Thesis has been accepted for inclusion in WVU Graduate Theses, Dissertations, and Problem Reports collection by an authorized administrator of The Research Repository @ WVU. For more information, please contact researchrepository@mail.wvu.edu. 
Persistence of Response Variation and Repetition

Adam H. Doughty

Thesis Submitted to the College of Arts and Sciences at West Virginia University

in partial fulfillment of the requirements for the degree of

\author{
Master of Arts \\ In \\ Psychology
}

\author{
Kennon A. Lattal, Ph.D., Chair \\ Michael Perone, Ph.D. \\ Hayne W. Reese, Ph.D. \\ Department of Psychology
}

Morgantown, West Virginia

2000

Keywords: Behavioral Persistence, Behavioral Variability, Behavioral Sterotypy, Reinforcement

Copyright 2000 Adam H. Doughty 


\section{ABSTRACT \\ Persistence of Response Variation and Repetition}

Adam H. Doughty

A multiple chained schedule was used to assess the persistence of fixed and variable response sequences. In one terminal link, a single 4-peck response sequence produced food (Repeat) and in the other terminal link a 4-peck response sequence produced food only if it had been occurring infrequently relative to the other 15 possible responses (Vary). Similar response and reinforcement rates occurred in each terminal link. Identical variable-interval 20-s schedules operated in the initial links preceding each terminal link and lower response rates reliably occurred in the initial link preceding the Vary terminal link. After responding stabilized under the multiple chained schedule, four disruption conditions were employed, one condition in which each pigeon was pre-fed before each session and three conditions in which a variable-time schedule, of three different values, operated during the inter-component intervals that preceded each initial link. During each of the four disruption conditions, response rate in each link of the chained schedule in the Vary component tended to be more persistent, relative to its own baseline level, than response rate in the Repeat component. During the pre-feeding condition, relative to baseline, the amount of variation in the Vary terminal link decreased slightly and the amount of repetition in the Repeat component remained similar. During the variable-time-schedule conditions, the amount of variation in the Vary component remained similar or decreased slightly, relative to baseline, while the amount of repetition in the Repeat component increased considerably. These results extend earlier findings demonstrating that response repetition is more susceptible to environmental disruption than is response variation. The results also suggest that theories of response strength, such as behavioral momentum theory, must take into account different response topographies. 


\section{Persistence of Response Variation and Repetition}

Table of Contents

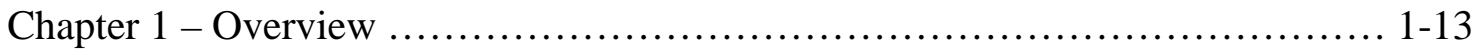

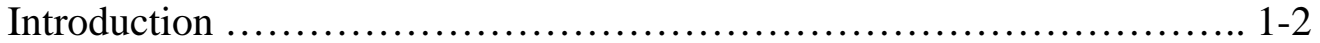

Literature Review ................................................ 2-12

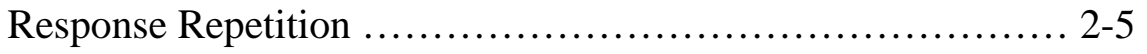

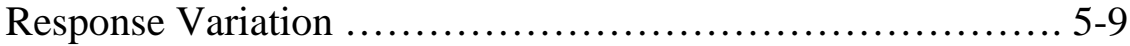

Response Strength ..................................... 9-12

Statement of the Problem ........................................... 12-13

Chapter 2 - Experimental Method and Results ............................. 14-35

Method ........................................................... 14-18

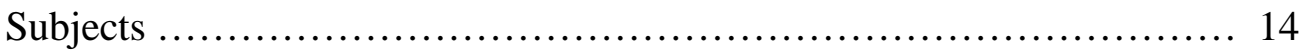

Apparatus ....................................................... 14

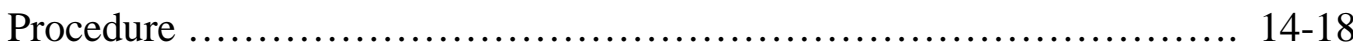

Results ..................................................... 20-35

Chapter 3 - Conclusions .................................................... 36-40

Discussion .................................................. 36-40

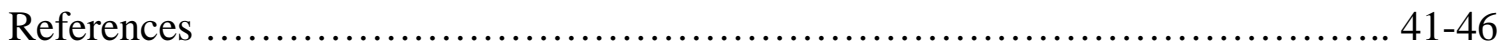




\section{Chapter 1. Overview}

\section{Introduction}

The selection and maintenance of responses by the environment is described by the principles of operant conditioning (e.g., Skinner, 1981). Operant conditioning describes the behavior of individual organisms as a function of their environment (e.g., Skinner, 1938). Much of operant conditioning examines the variables that influence response maintenance, however, a growing area of research is concerned with how these responses persist when the environment changes (e.g., Nevin, 1979). In a changed environment, the required response for reinforcement may be one that has occurred repeatedly in the past. In other circumstances, different responses may be required of an organism than had been occurring previously. This is true of a student confronted with a novel question, an artist creating an original piece of art or a wild animal attempting to elude a predator (Page \& Neuringer, 1985). Although response variation and repetition may, at different times, be confronted with a changing environment, little investigation of the relative persistence of these response topographies have occurred.

Variation within an organism's behavioral repertoire is necessary for a reinforcer to exert its effects (e.g., Skinner, 1938, 1981). As reinforcement operates, however, variation typically decreases as the repetition of selected responses increase (Schwartz, 1980; Skinner, 1948). Thus, although variation is necessary for the initial effects of reinforcement, repetition, the opposite of variation, is typically its outcome, unless response variation is explicitly reinforced (cf. Page \& Neuringer, 1985).

Although response variation and repetition can be acquired and maintained through reinforcement, there are few comparisons between these two response topographies. For example, if other things are equal, is one of these response topographies more persistent than the other? That is, is response variation or response repetition, in some sense, stronger (Nevin,1974; Skinner, 1938)? Many issues related to response variation may benefit from such an analysis of response persistence, including behavior labeled as creative (Holman, Goetz, \& Baer, 1977; Winston \& Baker, 1985), problem solving (Skinner, 1966), rule-governed and contingency-shaped (e.g., Joyce \& Chase, 1990), as well as behavior in applied or clinical settings (e.g., Mace, Lalli, Shea, 
Lalli, West, Roberts, \& Nevin, 1990).

\section{Literature Review}

Reinforcement can increase response variation (e.g., Page \& Neuringer, 1985) and/or response repetition (e.g., Skinner, 1948). Although both response variation and repetition can be maintained concurrently (Neuringer, 1992, 1993), the typical outcome of reinforcement is the acquisition and maintenance of one of these response topographies. Investigations comparing response variation and repetition, therefore, should allow more informed predictions about the controlling variables and properties of each.

This interest in determining the relative persistence of response variation and repetition is related to the concept of response strength (e.g., Nevin, 1974; Skinner, 1938). This concept is useful in the prediction and control of behavior by allowing for generality (Sidman, 1960) among situations differing in their use of subjects, procedures and measures of responding. In other words, response strength relates many independent and dependent variables to one another via a common concept or intervening variable (MacCorquodale \& Meehl, 1948). Techniques used to uncover some of the determinants of response strength have assessed response persistence in altered conditions (e.g., Nevin, 1992). Despite the interest and advances in the area of behavioral persistence, however, such an analysis has not been applied to response variation and repetition. The present experiment investigated the relative persistence of response variation and repetition.

\section{Response Repetition}

To behave repetitively is to emit the same response repeatedly. The consequence of continued reinforcement often is response repetition even when response variation would produce the same or higher rate of reinforcement (Schwartz, 1980, 1982a; Skinner, 1948; Vogel \& Annau, 1973).

Skinner (1948) demonstrated that reinforcement increases response repetition by delivering food to hungry pigeons independently of their behavior and observing that each pigeon emitted a stereotypic, idiosyncratic response. For example, one pigeon began to rotate counter-clockwise before each food presentation. This response occurred despite the fact that the pigeon would have received the same number of food 
presentations if its responding had varied, but instead, because of the reinforcement process, the response that preceded the reinforcer continued (cf. Schaal, Shahan, Kovera, \& Reilly, 1998; but see Staddon \& Simmelhag, 1971; Timberlake \& Lucas, 1985 for a different interpretation of the data).

Skinner's (1948) demonstration of the repetition-enhancing effects of reinforcement involved a schedule of response-independent food delivery. Vogel and Annau (1973) established a repetitive response using a schedule of response-dependent reinforcement that also allowed for response variation. Each of five pigeons pecked two keys to move a light from an upper left stimulus to a lower right stimulus in a $4 \mathrm{x} 4$ matrix of stimulus lights. A peck to the left key moved the light down and a peck to the right key moved the light to the right. Vogel and Annau noted that each pigeon initially emitted their responses in a variable manner between the two keys but, with continued reinforcement, only a single stereotypic, idiosyncratic response sequence occurred. As with Skinner (1948), response repetition occurred even though (a) reinforcers were delivered independently of a particular response and (b) such response variation would have produced the same rate of reinforcement.

Another demonstration that reinforcement creates response repetition was conducted by Schwartz (1980 Experiment 1). In a procedure similar to that used by Vogel and Annau (1973), each of 12 pigeons pecked two keys to move a light from an upper left stimulus light to a lower right stimulus light in a 5x5 matrix. Four pecks were required to each key to obtain a reinforcer and a fifth peck to the same key initiated an immediate timeout (all lights were darkened and food was unavailable) that then was followed by another trial. Approximately 110 different response sequences were emitted per pigeon during the first five 50-trial sessions. During Sessions 36 through 40, this number decreased to 29. The number of reinforcers received per pigeon increased from approximately 51, during Sessions 1 through 5, to 169, during Sessions 36 through 40. Thus, although 70 different response sequences could produce food, with continued reinforcement, each pigeon repeatedly emitted the same response sequence. Although the number of different response sequences decreased, the number of reinforcers obtained increased threefold. 
The research described above suggested that the typical outcome of reinforcement is response repetition, however, in each study response variation was not required to produce a reinforcer. Consequently, repeating response sequences did not decrease the probability of obtaining a reinforcer. Schwartz (1980 Experiment 4), using the same procedure (and eight of the same pigeons) described above, attempted to produce a different response sequence each trial, such that response variation was now necessary because repeating the same response sequence would no longer produce a reinforcer. Following forty 50-trial sessions, however, response variation did not increase substantially. The number of different response sequences during Sessions 1 through 5 increased from approximately 28, to only about 35, during Sessions 36 through 40 . The number of reinforcers obtained during Sessions 1 through 5 increased from approximately 79 , to only about 90 , during Sessions 36 through 40. Schwartz tentatively suggested that, although response variation sometimes may be more effective in obtaining reinforcers, the outcome of continued reinforcement is response repetition.

To examine whether response repetition is typically the outcome of continued reinforcement, Schwartz (1982a) used a slightly different procedure than that described above in an attempt to reinforce response variation. The first procedural difference was that, to decrease the probability of any behavioral history effects (e.g., Freeman \& Lattal, 1992), experimentally naïve pigeons were used rather than those with a history of emitting repetitive response sequences. The second procedural difference was that the time between trials was decreased from $10 \mathrm{~s}$ to $0.5 \mathrm{~s}$ so that the pigeons did not have to "bridge a 10-sec delay between what they had just done and what they would do next" (Schwartz, 1982a, p. 172). Thus, each pigeon had to emit an 8-peck response sequence that consisted of four pecks to each key (again a fifth peck to the same key initiated an immediate timeout) and which differed from the preceding response sequence. Consequently, each of 70 different response sequences could produce a reinforcer during each 50-trial session. Despite the procedural changes designed to promote response variation, response repetition again dominated. Following 100 sessions, only one pigeon obtained over 20 reinforcers per session. For each pigeon, the number of different response sequences in the last five sessions decreased compared to the first 5 sessions. 
Thus, response repetition occurred despite making food dependent on such variation.

The research summarized above demonstrated that a reinforcer can concurrently result in response repetition (even when response variation would have produced a higher rate of reinforcement) and select extended response sequences from an organism's behavioral repertoire. The formation of extended response sequences has been noted elsewhere (e.g., Arbuckle \& Lattal, 1988; Schwartz, 1982b), in that they are modified by their consequences in similar ways as single response sequences are.

\section{Response Variation}

To behave variably is to emit different responses. In describing the repetitionenhancing effects of reinforcement, Schwartz (1980, 1982a) concluded that response variation could not be controlled by its consequences. There are, however, a number of demonstrations that contradict Schwartz's conclusion (Blough, 1966; Bryant \& Church, 1974; Holman et al., 1977; Machado, 1989, 1992, 1993, 1997; Morris, 1987; Page \& Neuringer, 1985; Pryor, Haag, \& O’Reilly,1969; Shimp, 1967).

Some of the initial demonstrations of the reinforcement of response variation involved reinforcing least-frequently observed responses (Blough, 1966; Pryor et al., 1969; Shimp, 1967). For example, Blough (1966) reinforced interresponse times (IRTs) that were momentarily least frequent. Each IRT was placed in a bin and if that bin contained, at that moment, the least number of IRTs, food was delivered. The resulting IRT distribution of each pigeon approximated that of an ideal random generator. Shimp (1967) used a 2-key procedure and also reinforced the responding of pigeons using a least-frequent procedure. A 4-peck response sequence was reinforced if that response sequence was, at that moment, the least-frequent. Variable four-peck response sequences were acquired and maintained (see also Bryant \& Church, 1974).

The significance of reinforcing response variation has implications for investigations of what has been labeled creative behavior, in that novel responses sometimes are adaptive in new situations (Holman et al., 1977; Pryor et al., 1969). Pryor et al. (1969) reinforced swimming and leaping responses of porpoises if those responses had never been demonstrated before. The result was the occurrence of responses previously not observed in that species (Steno bredanensis). Holman et al. (1977) 
reinforced artistic responses of children if those responses had not occurred either in that session (some conditions) or in any of the prior sessions (other conditions). Results comparable to the porpoises were obtained with the children, in that novel responses occurred relatively frequently.

The preceding research demonstrated that response variation could be reinforced. Page and Neuringer (1985) also reported that response variation was a conditionable property of behavior. In six experiments, pigeons and rats obtained food by emitting a response sequence on two operanda which differed from the last $x$ response sequences $(\operatorname{Lag} x)$. In each experiment, a trial began with the illumination of two response keys (for the pigeons) and after a peck to either key both keys were darkened for $0.5 \mathrm{~s}$ and then turned on. Following another peck to either key, both keys again were darkened for $0.5 \mathrm{~s}$ and then again turned on. This continued until eight pecks occurred and immediately following the eighth peck one of two consequences followed. If the 8-peck response sequence differed from the last $x$ response sequences, then food was delivered. If the 8peck response sequence repeated one of the last $x$ response sequences, then a blackout occurred (all lights were darkened and food was not delivered). Following a food delivery or a blackout, both keys were illuminated and a new trial began.

Page and Neuringer's (1985) first two experiments employed procedures that were both similar to (Experiment 1) and different from (Experiment 2) those used by Schwartz (1980, 1982a). The same pigeons responded repetitively in the procedure similar to that used by Schwartz and variably when the procedure differed from that used by Schwartz. Specifically, an 8-peck response sequence was reinforced in pigeons with and without the four-pecks-to-a-key requirement used by Schwartz. In the variabilityonly condition, one pigeon received food for emitting an 8-peck response sequence under a Lag-1 contingency and three pigeons received food for emitting an 8-peck response sequence under a Lag-5 contingency. In the condition requiring a peck to each key four times, each pigeon received food for emitting such an 8-peck response sequence under a Lag-1 contingency. Without the 4-pecks-to-a-key requirement, the percent of reinforced trials per session was about $90 \%$, and with the requirement, it was near $40 \%$. Thus, the 4-pecks-to-a-key requirement imposed by Schwartz was suggested by Page and 
Neuringer to be crucial in producing response repetition.

Another difference between the procedures used by Schwartz (1980, 1982a) and Page and Neuringer (1985) was the presence or absence of a 0.5-s blackout between pecks (inter-peck interval; IPI). In Page and Neuringer's procedure, following each key peck (except for the eighth one) the key was darkened for $0.5 \mathrm{~s}$, whereas in Schwartz's procedure this did not occur. This manipulation changed the procedure from a freeoperant procedure to a discrete-response procedure. Morris (1987) noted this and suggested that in the free-operant procedure the Pavlovian contingency (the relation between reinforcers and stimuli) might have masked the operant contingency (the relation between reinforcers and responses) which reinforced response variation. Morris examined these relations by requiring two pigeons to peck four times to two response keys in the presence of a Lag- 2 contingency under both a free-operant procedure and a discrete-response procedure. Under the discrete-response procedure, a 0.5-s IPI was employed, whereas under the free-operant procedure, the keys remained illuminated following a peck. The same pigeons received about $30 \%$ of the available reinforcers per session under the free-operant procedure and about $75 \%$ of the available reinforcers under the discrete-response procedure. Thus, Morris demonstrated that the repetitive responding observed by Schwartz $(1980,1982$ a) also was due in part to Pavlovian processes operating in Schwartz's free-operant procedure.

To extend the notion that response variation could be controlled by its consequences, Page and Neuringer (1985) demonstrated that response variation only occurred when a contingency required it. Pigeons initially responded under a Lag-50 contingency in which $70 \%$ of the response sequences emitted per session were different. In the next condition, a yoked variable-ratio (VR) schedule was effected in which food presentations occurred after the same number of response sequences that were emitted in the preceding condition, for each pigeon, regardless of the pattern of responding. Thus, in the yoked VR condition, response variation was permitted but not required to obtain food. Under this contingency, only $20 \%$ of the response sequences emitted per session were different. Therefore, response variation occurred when it was required to produce a reinforcer and response repetition occurred when response variation was not required to 
produce a reinforcer (see also Hunziker, Saldana, \& Neuringer, 1996; Machado, 1989 1992).

Another controlling variable of a response is the presence or absence of a discriminative stimulus. Page and Neuringer (1985) used a multiple schedule to demonstrate that response variation and response repetition could be placed under discriminative stimulus control. Multiple schedules consist of at least two different components each occurring in the same session and each correlated with a distinct stimulus (Ferster \& Skinner, 1957). Pigeons emitted 5-peck response sequences under a Lag-10 contingency to two blue key lights and emitted the same 5-peck response sequence (LRRLL, where $\mathrm{L}$ is a left key response and $\mathrm{R}$ is a right key response) to two red key lights. Each pigeon responded variably when the keys were blue and repetitively when they were red (see also Cohen, Neuringer, \& Rhodes, 1990; Denney \& Neuringer, 1998). Employing a variant of a least-frequent procedure (Blough, 1966; Shimp, 1967), Denney and Neuringer (1998) also demonstrated that variable response sequences could be brought under stimulus control. In this procedure, similar reinforcement rates occurred in each component of a 2-component multiple schedule. Variable response sequences were reinforced in one component (Vary component) and reinforcers were delivered independently of response-sequence patterns in the second component (Yoked component). In the Vary component, a 4-peck response sequence to two keys (e.g., LRRL) was reinforced if its weighted relative frequency was less than some threshold value. The relative frequency of a response sequence was calculated by dividing the number of times it occurred in a session by the total number of 4-peck response sequences in that session. If that number was less than or equal to a threshold value (e.g., 0.09), then food was delivered. The weighted relative frequency was obtained after each food delivery by multiplying the relative frequency of each response sequence by a weighting coefficient. The weighting coefficient was used so that recent response sequences were weighed more heavily than nonrecent ones. In summary, infrequently occurring response sequences were reinforced (i.e., those occurring less than or equal to $9 \%$ of the time) and frequently occurring response sequences were not. In the Yoked component, reinforcement was probabilistic and derived separately for each pigeon from 
the Vary component, such that reinforcement rates in the two components were similar. That is, following each 4-peck response sequence a reinforcer was delivered, according to some probability, independently of the sequence of response sequences.

Response variation was higher when it was reinforced than when it was not. In a second experiment, when the all the stimuli were absent for a single session, the rate of response variation in the two components converged. In the next session, when the stimuli were reinstated, the rate of variable response sequences in the two components separated, suggesting that it was, in fact, the stimuli that were controlling the variable responding. Thus, Denney and Neuringer (1998) demonstrated that response variation could be placed under stimulus control and also, like response repetition, response variation is a conditionable property of behavior.

\section{Response Strength}

Skinner (1938) equated response strength with response rate. The problem with conceptualizing response strength simply as rate of occurrence is that rate is a conditionable property of responding. That is, identical reinforcement rates can maintain both high response rates on a fixed-ratio (FR) schedule and low response rates on a differential-reinforcement-of-low-rate (DRL) schedule (Kramer \& Rilling, 1970). Furthermore, at similar reinforcement rates, responding maintained by a DRL schedule is stronger than responding maintained by an FR schedule (Lattal, 1989; see also Blackman, 1968; Nevin, 1974), when resistance to change (see below) is the index of response strength.

Nevin (1974), expanding on well-established methods in the psychology of learning (see Nevin, 1979), proposed resistance to change as a method for studying response strength. Resistance-to-change techniques typically use multiple schedules with different reinforcement schedules in each component; extinction, satiation, alternative reinforcement or response-independent reinforcement delivered during inter-component intervals (ICIs) as disrupters; and proportion of baseline response rates as dependent variables. When a disrupting operation is applied to two different responses, the resistance of each response is determined by comparing the resulting change of each response relative to its own baseline during the pre-disrupter period. Consequently, the 
response that changes less, or is more persistent, is considered to be stronger. Nevin (1974) investigated the relative strength of pigeon's key pecking maintained on 3component multiple schedules. In one component, a variable-interval (VI) schedule operated on a single key illuminated one color and in another component, another VI schedule operated in the presence of a different key color. These two components each lasted $60 \mathrm{~s}$, alternated irregularly within a session and always were separated by a third component, which lasted $30 \mathrm{~s}$ and in which the key light was turned off (i.e., the ICI). In the different experiments, the two components differed in reinforcement rate, reinforcer magnitude or the duration of a signaled delay to the reinforcer. After responding stabilized, responding was disrupted in two ways. In some conditions varying amounts of response-independent food were delivered during the ICIs according to variable-time (VT) schedules. In another condition, responding in the two formerly VI components was extinguished. Response rates decreased in the presence of either disrupter. More importantly, responding maintained by higher reinforcement rates, larger reinforcer magnitudes and shorter signaled delays to reinforcement persisted longer than responding maintained by lower reinforcement rates, smaller reinforcer magnitudes and longer signaled delays to reinforcement. Because responding systematically changed less in certain situations than others, Nevin concluded that such resistance-to-change techniques provide a useful assessment of response strength.

Response strength subsequently has been described quantitatively as behavioral momentum (Nevin, 1992; Nevin, Atak, \& Mandell, 1983) and the analysis has been applied to a variety of reinforcement situations (Nevin, 1979, 1988, 1992, 1995). The general finding has been that responding maintained by higher reinforcement rates is more resistant to change than that maintained by lower reinforcement rates, independently of the baseline rate of responding during the pre-disrupter period (Nevin, 1984; Nevin, Smith, \& Roberts, 1987; Nevin, Tota, Torquato, \& Shull, 1990). Nevin et al. (1990 Experiment 1) initially trained pigeons to respond on multiple schedules with identical VI schedules in each component. Lower response rates were produced in one of the components by conjointly delivering additional response-independent reinforcement (Lattal, 1974). Responding then was disrupted by extinction and by pre-session feeding 
(i.e., satiation). Despite the fact that lower response rates occurred in the component with additional response-independent reinforcement, responding in this component was more resistant to change, presumably because the overall rate of reinforcement was greater. Therefore, the operant contingency has been suggested to determine the rate of responding whereas the Pavlovian contingency has been suggested to determine the resistance of responding to change (but see Bell, 1999; Grace, Schwendiman, \& Nevin, 1998 for instances in which the operant contingency influenced resistance to change independently of the Pavlovian contingency).

Because it has been suggested that the strength of a response is determined solely by its context of reinforcement, it is possible to study the relative persistence of two responses by arranging similar and/or dissimilar rates of reinforcement in two components of a multiple schedule. Responding then can be disrupted in several ways and response strength can be assessed. One useful procedure for investigating response persistence is a multiple chained schedule of reinforcement (Mellon \& Shull, 1986; Nevin, Mandell, \& Yarensky, 1981). In a two-link chained schedule, responding in an initial link is maintained by the stimulus correlated with the terminal link and responding in the terminal link is maintained by primary reinforcement (Ferster \& Skinner, 1957). Thus in a multiple chained schedule, one chained schedule operates in the presence of one discriminative stimulus and a second chained schedule operates in the presence of another. Nevin et al. (1981) arranged identical random-interval (RI) schedules in the initial links of two chained schedules and varied reinforcer density (reinforcer rate multiplied by reinforcer duration) in the terminal links under RI schedules. Responding then was disrupted by pre-feeding and signaled concurrent reinforcement, that is after varying amounts of time a separate key became lit and food was delivered for a single response to it. Two main findings were obtained. First, terminal-link responding was more persistent than initial-link responding. Second, responding in the component maintained by the higher reinforcer density was more resistant to disruption than responding in the component maintained by the lower reinforcer density. This latter finding is consistent with results from multiple schedules with simple schedules in either component (e.g., Nevin, 1974), thus, validating the use of multiple chained schedules to 
assess response persistence.

\section{Statement of the Problem}

The typical effect of reinforcement is decreased response variation, including such dimensions in responding as location, duration, force, and topography (e.g., Antonitis, 1951; Marguiles, 1961; Notterman \& Mintz, 1965; Vogel \& Annau, 1973). Vogel and Annau (1973) established a repetitive response topography consisting of combinations of left and right-key pecks in pigeons under a discrete-trials procedure. At the start of each trial, only an upper-left stimulus light of a $4 \mathrm{X} 4$ matrix of stimulus lights was on and a response to a left key moved the stimulus light down (the matrix) and a peck to a right response key moved the stimulus light to the right. Food was delivered following a 6-peck response sequence that resulted in the stimulus light moving to the lower right position of the matrix. Vogel and Annau (1973) reported that each pigeon initially emitted a variety of response sequences but with continued reinforcement only a single repetitive response sequence occurred. Page and Neuringer (1985) suggested that decreased response variation of the sort described by Vogel and Annau (1973) only occurs under conditions in which such variation is not specified as a condition for reinforcement. When Page and Neuringer (1985 Experiment 3) only reinforced 8-peck response sequences in pigeons that were different than the previous 50 response sequences, an average of $67 \%$ of the trials ended in reinforcement.

Because reinforcement typically induces response repetition and response variation normally only occurs when it is explicitly reinforced, questions arise concerning whether there are functional differences between these two response topographies (e.g., Neuringer, 1991). For example, is response repetition, in some sense, more fundamental or natural? Or from a more behavior-analytic viewpoint, might response repetition be stronger, or more resistant to environmental disruption, than response variation? Neuringer (1991) suggested the opposite to be true, that is, repetitive response sequences might be more susceptible to disruption than variable response sequences. Following alcohol administration, response variation in rats increased in each component of a multiple schedule in which variable response sequences were reinforced in one component (Vary) and a single fixed response sequence was reinforced in the other 
(Repeat) (Cohen, Rhodes \& Neuringer, 1990). In the Repeat component, this increased variation occurred even though such variation reduced reinforcement rate, whereas reinforcement rate remained approximately the same in the Vary component. In an earlier assessment of the resistance of response variation, Neuringer (1991 Experiment 2) systematically varied the time between individual responses (IRTs) within 4-response sequences. For rats in one group, variable response sequences were reinforced and for those in another group only a single response sequence was reinforced. As the IRT increased from 0.5 to $20 \mathrm{~s}$, response variation increased in each component. This increase differentially affected reinforcement probability in the two components (cf. also Cohen et al., 1990). Neuringer concluded that, at least under alcohol administration and IRT manipulation, variable response sequences are more resistant to disruption than are repetitive ones. Because resistance to disruption was measured primarily by changes in the percentage of reinforced response sequences in each component the similarity of these resistance-to-change measures to more typical response-strength manipulations (e.g., Nevin, 1974) is unknown. A more conventional resistance-to-change analysis consisting of disrupting responding under multiple schedules of reinforcement through satiation, response-independent food delivered between the multiple-schedule components, or extinction, applied to varied and repeated response sequences would clarify Neuringer's (1991) initial observations about the relative strength of variable and repetitive responding.

Nevin (1992) asserted that reinforcement rate solely determines the resistance of responding to change, which suggests that so long as that rate is constant, response topography should not affect response strength. This assertion is at odds with Neuringer's (1991) suggestions about variable versus repetitive responding, suggestions that also have found some support in the work of Grace et al. (1998), who suggested that different response topographies may be differentially susceptible to change, despite similar reinforcement rates. Thus, in the present experiment, the relative resistance of variable and repetitive response sequences was examined as a function of both presession feeding and the delivery of response-independent food during separate components between the schedules controlling these two response topographies. 
Chapter 2 - Experimental Method and Results.

Method

Subjects

Each of three experimentally naïve male White Carneau pigeons, 11, 12 and 14, were used. Pigeon 11 was maintained at $80 \%$ of its free-feeding weight, Pigeon 12 was maintained at $75 \%$ of its free-feeding weight and Pigeon 14 was maintained at $72 \%$ of its free-feeding weight. Pigeons 12 and 14 were maintained at lower percentages of their free-feeding body weights because early in training responding was not maintained at their original $80 \%$ body weight throughout the session. Each pigeon was housed individually and water and health grit were available continuously in each home cage. Each was fed mixed grain following its session, if necessary, to maintain its target body weight.

Apparatus

A standard 3-key operant conditioning chamber, with a work area $35 \mathrm{~cm}$ high by $30 \mathrm{~cm}$ wide by $30 \mathrm{~cm}$ long, enclosed in a sound-attenuating box was used. White noise was presented via a speaker located $4 \mathrm{~cm}$ below the right response key. Each response key ( $2 \mathrm{~cm}$ diameter) was located on the front wall and could be transilluminated red or white via 28VDC bulbs. A 28VDC white houselight located in the lower right corner of the front wall remained on throughout the session except during the blackouts (see below) and reinforcement. The key lights also were darkened during reinforcement, which was access to mixed grain delivered in a food hopper located behind a feeder aperture, $5 \mathrm{~cm}$ square, centered on the front wall with its lower edge $5 \mathrm{~cm}$ above the floor. The aperture was transilluminated white by a $28 \mathrm{VDC}$ bulb during food delivery. Programming and data recording were controlled by a computer in an adjacent room using MED-PC® software (MED Associates, Inc. \& Tatham, 1991).

Procedure

Following one session of magazine training, key pecking for each pigeon was autoshaped to each of the three keys (red and white) by transilluminating one of the keys red or white following an inter-trial interval averaging $120 \mathrm{~s}$, in which all the key lights were darkened and the houselight was on. If a peck did not occur to the transilluminated 
key within $6 \mathrm{~s}$, then it and the houselight were darkened and the hopper was raised for 4 s. If a peck occurred to the transilluminated key within $6 \mathrm{~s}$, then it and the houselight were darkened and the hopper was raised immediately. Each autoshaping session consisted of 60 trials, 10 trials with each key red and 10 trials with each key white. After reliable pecking in the presence of each key color was established, two additional autoshaping sessions occurred.

Three supplementary training conditions then occurred for each pigeon in which a single 4-peck response sequence (LRLR) was reinforced. This training occurred because it had been noted previously that the training of a single 4-peck response sequence often took longer than the training of variable response sequences (Cohen et al., 1990; see also Page \& Neuringer, 1985). In each of these conditions, the houselight remained on at all times, except during reinforcer delivery and a blackout (see below), and each session began with the illumination of the middle key. A VI 20-s schedule operated on the middle key (with the two side keys darkened) such that following an average of $20 \mathrm{~s}$, a single peck to the middle key darkened it and immediately turned on the left key light. A peck to the left key then darkened it for $0.5 \mathrm{~s}$. Following a 0.5-s IPI (a key peck reset the 0.5 -s interval), the right key was tuned on and a peck to it darkened it for $0.5 \mathrm{~s}$. The left key then was turned on and a peck to it darkened it for $0.5 \mathrm{~s}$ after which the right key was again turned on. A right key peck then darkened it and produced an immediate reinforcer. Following a reinforcer, the left key was tuned on and the same procedure operated. After the delivery of five consecutive reinforcers, the middle key was illuminated and the same procedure as above operated. Each session ended after 60 reinforcers. This training continued until each pigeon was reliably pecking each key within $1 \mathrm{~s}$ of it becoming transilluminated.

In the next training condition, which lasted approximately five sessions, the same procedure operated except that both the left and right keylights were turned on following each key peck. Each 'incorrect' key peck, that is a right-key peck in the first or third position of the sequence or a left-key peck in the second or fourth position of the sequence, darkened both keys for $3 \mathrm{~s}$ and reset the trial. In the next and final training 
condition, the same procedure as above operated except that an 'incorrect' key peck did not produce any programmed consequences. This condition continued until each pigeon completed the LRLR response sequence on approximately $80 \%$ of the trials.

Following the LRLR training described above, a 3-component multiple schedule was effected in which a separate 2-link chained schedule operated in two of the components. In each session, these two components each lasted approximately $60 \mathrm{~s}$ (see below) and strictly alternated until each occurred 20 times (the first component was chosen randomly by the computer) and a 30-s ICI (the third component) preceded each main component. During an ICI, only the houselight remained illuminated. In addition, there was a 10-min timeout for Pigeon 14 prior to each session, in which all the lights were darkened, because early in training it was noted that this pigeon often did not respond often early in the trial.

In the initial links of either chained schedule, the middle key was either red, hereafter referred to as the Repeat component, or white, hereafter referred to as the Vary component, and the two side keys were darkened. In each of these links, a VI 20-s schedule operated. Each of these schedules was composed of 10 intervals derived according to a modified version of the constant probability distribution described by Fleshler and Hoffman (1962). That is, the longer interreinforcer intervals were shortened, the intermediate interreinforcer intervals were lengthened and the shorter interreinforcer intervals remained the same. Following completion of this schedule, the middle key was darkened and the two side keys were transilluminated immediately. Each component then continued in the terminal link until the first completed 4-peck response sequence and its programmed consequence (see below) occurred following $60 \mathrm{~s}$ since the onset of the initial link.

In the terminal link of the Repeat component, the two side keys were red and in the terminal link of the Vary component they were white. In each of these terminal links, a discrete-response procedure (Morris, 1987; Page \& Neuringer, 1985) operated such that four pecks constituted a response sequence. Following each of the first 3 pecks, a $0.5-\mathrm{s}$ IPI operated and immediately following the fourth peck, one of two programmed 
consequences occurred. The programmed consequences were either a 2- or 3-s reinforcer delivery or a 2- or 3-s blackout, in which all the lights were darkened. For Pigeon 11, the reinforcer deliveries and blackouts were $3 \mathrm{~s}$ and for Pigeons 12 and 14 they were $2 \mathrm{~s}$.

In the Repeat component, each pigeon received food only following a LRLR response sequence. In addition, this response sequence produced a reinforcer probabilistically (otherwise a blackout occurred). This reinforcement probability was calculated separately for each pigeon to maintain similar reinforcement rates in the two components and was changed, if necessary, at the beginning of each session. Any response sequence other than LRLR produced the blackout as noted in the preceding paragraph.

In the Vary component, each pigeon was required to emit a 4-peck response sequence with weighted relative frequency that was less than some threshold value (cf. Denney \& Neuringer, 1998). Specifically, a relative frequency following each response sequence was calculated by dividing the number of times that response had occurred by the total number of responses emitted (the entire experiment was treated as one long session in that the relative frequencies depended on each preceding session). If the relative frequency of the response sequence was less than or equal to 0.05 , then a reinforcer was delivered and if that relative frequency was greater than 0.05 , then a blackout occurred. Following each reinforcer delivery, each of the 16 relative frequencies was multiplied by a weighting coefficient ( 0.95 ; Denney \& Neuringer, 1998) so that recent response sequences were weighed more heavily than nonrecent ones. Simply stated, a response sequence was reinforced if it had been occurring less than or equal to $5 \%$ of the time, relative to the other 15 possible response sequences.

After stable responding was established in each link in the Repeat and Vary components, defined as the absence of a trend for at least six consecutive sessions in initial and terminal link response rates, reinforcement rates and levels of repetition and variation, as indexed by their uncertainty value (U-Value; see below), two types of disrupters were introduced. The first was pre-session feeding (i.e., satiation). Each pigeon was fed increasing amounts of grain $30 \mathrm{~min}$ prior to several consecutive sessions until a session occurred in which a key peck was absent for 10 consecutive min. The 
amounts of grain used in consecutive sessions were $5 \mathrm{~g}, 5 \mathrm{~g}, 5 \mathrm{~g}, 7.5 \mathrm{~g}, 7.5 \mathrm{~g}, 7.5 \mathrm{~g}, 12.5$

$\mathrm{g}, 12.5 \mathrm{~g}, 12.5 \mathrm{~g}$ and $22.5 \mathrm{~g}$. After each pigeon's body weight returned to its target weight, the multiple chained schedule operated for at least 10 additional sessions, and until stable responding again was obtained, before the second disrupter was introduced. The second disrupter was the delivery of food according to a VT schedule during the 30-s ICI's. VT schedules of 15,5 , and $2.5 \mathrm{~s}$ were used, in that order. Five sessions at each of these values occurred and the multiple chained schedule operated for at least 10 sessions prior to each VT schedule. A VT schedule session occurred only if the pigeon's body weight was within $+/-20 \mathrm{~g}$ of its target weight. Table 1 shows the number of sessions in each condition, excluding the training conditions, for each pigeon. 
Table 1. Number of sessions and mean and standard deviation of reinforcement rates (reinforcers per min) in each condition, in order of occurrence, for each pigeon. The labels V and R refer to the Vary and Repeat components, respectively. Means and standard deviations are for the last six sessions of each baseline condition and each session of each of the four disruption conditions. The baseline condition is a multiple chained schedule (as described in the text).

\begin{tabular}{|c|c|c|c|c|c|c|c|c|c|}
\hline \multirow{2}{*}{$\begin{array}{l}\text { Condition } \\
\text { baseline }\end{array}$} & \multicolumn{3}{|c|}{ Pigeon 12} & & Pigeon 14 & 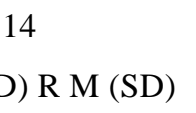 & \multicolumn{3}{|c|}{ Pigeon 11} \\
\hline & 88 & $3.06(.46)$ & $3.44(.40)$ & 86 & $3.26(.55)$ & $2.90(.27)$ & 73 & $3.52(.44)$ & $3.92(.59)$ \\
\hline pre-feeding & 10 & $2.34(.54)$ & $2.67(.73)$ & 7 & $2.11(.42)$ & $2.62(.37)$ & 9 & $3.15(1.08)$ & $2.12(1.22)$ \\
\hline baseline & 38 & $2.16(.15)$ & $2.23(.25)$ & 39 & $2.65(.31)$ & $2.82(.87)$ & 30 & $3.58(.93)$ & $3.50(.90)$ \\
\hline VT $15 \mathrm{~s}$ & 5 & $2.52(.23)$ & $1.86(.79)$ & 5 & $1.88(.53)$ & $2.13(1.05)$ & 5 & $2.29(1.07)$ & $3.18(.57)$ \\
\hline baseline & 18 & $2.50(.38)$ & $2.77(.31)$ & 25 & $2.55(.23)$ & $2.64(.63)$ & 15 & $3.70(.77)$ & $3.80(.92)$ \\
\hline VT $5 \mathrm{~s}$ & 5 & $2.32(.62)$ & $2.12(.70)$ & 5 & $3.63(.77)$ & $2.75(.66)$ & 5 & 3.03 (1.34) & $2.88(.82)$ \\
\hline baseline & 16 & $2.36(.38)$ & $2.41(.44)$ & 15 & $3.15(.62)$ & $3.26(.69)$ & 18 & $4.01(.46)$ & $4.09(.51)$ \\
\hline VT $2.5 \mathrm{~s}$ & 5 & $2.03(.68)$ & $1.77(.75)$ & 5 & $2.53(.80)$ & $2.35(1.62)$ & 5 & $2.37(.40)$ & $2.53(1.66)$ \\
\hline
\end{tabular}




\section{Results}

The mean number of reinforcers obtained per minute (and standard deviations) for the Vary and Repeat components during the last six sessions preceding each of the four disruption conditions (one pre-feeding condition and three VT-schedule conditions) and during the disruption conditions are shown in Table 1. Throughout each condition, there were no systematic reinforcement rate differences between the two components and the absolute reinforcement rate differences between the two components were relatively small, demonstrating the effectiveness of the yoking procedure.

Figure 1 shows the mean (and standard deviation) initial (left graphs) and terminal-link (right graphs) responses (response sequences, for the latter) per minute in both the Vary and Repeat components during the last six sessions preceding each of the four disruption conditions for each pigeon. Initial-link response rates were calculated by dividing the number of responses to the middle key by the amount of time that key was on and terminal-link response rates were calculated by dividing the number of 4-peck response sequences in a link by the amount of time spent in that link (reinforcement and blackout time was excluded). In general, response rates in the initial link preceding the Vary terminal link were lower than in the initial link preceding the Repeat terminal link. Terminal-link response rates were similar in each component for each pigeon.

Figure 2 shows the degree of variation and repetition for each pigeon during the baseline conditions. Displayed are the relative frequencies of each of the 16 possible response sequences obtained for each pigeon in each component. These relative frequencies were obtained from the three baseline sessions that preceded each of the four disruption conditions, for a total of 12 sessions for each pigeon. The average U-values from these sessions are shown in the middle of each panel and the solid horizontal lines on the panels on the left side of the figure show the predicted relative frequencies of each response according to chance (i.e., 0.0625 or 1 divided by 16). U-values (Miller \& Frick, 1949; Page \& Neuringer, 1985) were calculated according to the formula:

$$
\left[\mathrm{U}=-\Sigma\left[\left(\mathrm{Rf}_{\mathrm{i}} * \log _{2}\left(\mathrm{Rf}_{\mathrm{i}}\right)\right] / \log _{2}(16)\right]\right.
$$

where $\mathrm{Rf}_{\mathrm{i}}$ is the relative frequency of each of the 16 possible response sequences. A Uvalue of 1 implies complete uncertainty, or variation, and a U-value of 0 implies 


\section{Next Page}

$\underline{\text { Figure 1. }}$ Mean (and standard deviation) initial (left graphs) and terminal-link (right graphs) responses (response sequences, for the latter) per minute in both the Vary and Repeat components during the last six sessions preceding each of the four disruption conditions for each pigeon. 


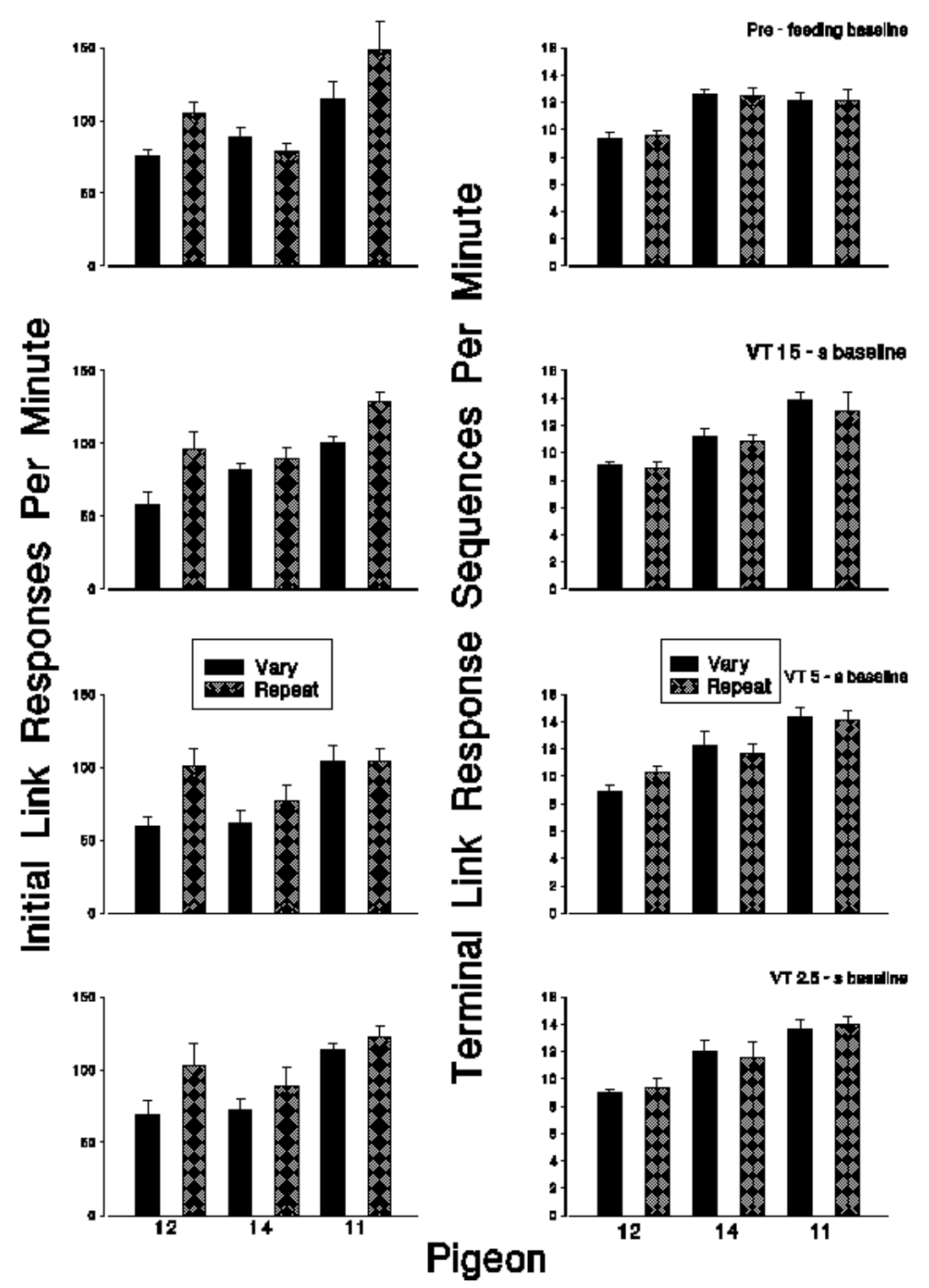




\begin{abstract}
Next Page
Figure 2. Relative frequencies of each of the 16 possible response sequences obtained for each pigeon in each component from the three baseline sessions that preceded each of the four disruption conditions, for a total of 12 sessions for each pigeon. The average Uvalues (see text) from these sessions are shown in the middle of each panel and the solid horizontal lines on the panels on the left side of the figure show the predicted relative frequencies of each response sequence according to chance.
\end{abstract}



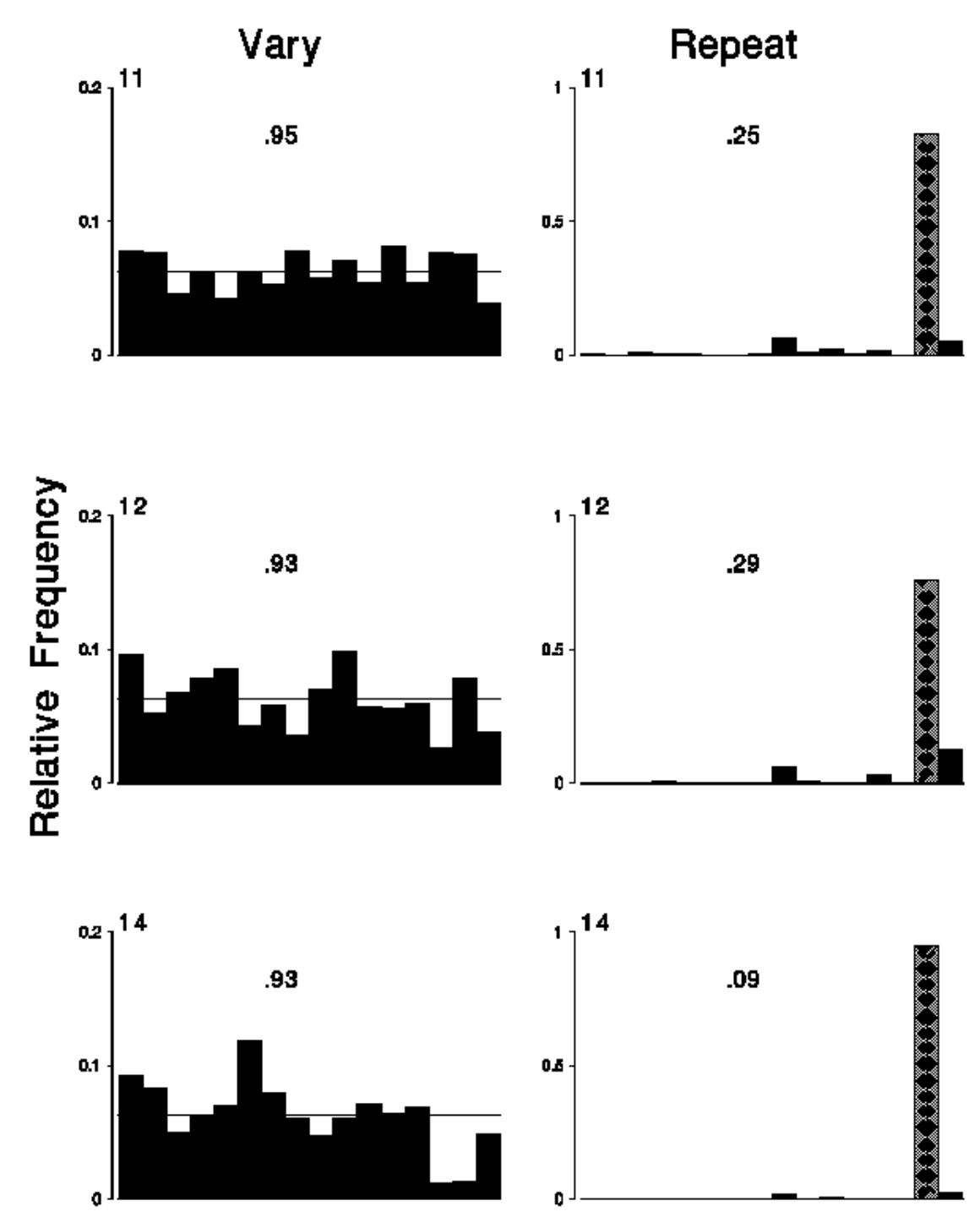

Response Sequences 
complete certainty, or repetition. In other words, higher U-values indicate higher levels of variation, or, conversely lower levels of repetition, and lower U-values indicate lower levels of variation, or, conversely, higher levels of repetition. The 16 response sequences are plotted along the $\mathrm{X}$-axis such that the leftmost response sequences contain the least number of changeovers (i.e., LLLL and RRRR) and the rightmost response sequences contain the most number of changeovers (i.e., LRLR and RLRL). Each of the 16 response sequences were emitted near chance level in the Vary terminal link while LRLR, the response sequence that produced food in the Repeat terminal link, occurred most frequently in that link. In the Vary component, similar U-values were obtained for each pigeon while the U-values obtained in the Repeat component showed higher levels of inter-subject variability.

Figure 3 shows the log proportion of baseline responses per minute in the initial and terminal links of each component for each pigeon during each pre-feeding session. These data allow for a comparison between response rates despite absolute response rate differences during baseline (Nevin, 1974). Proportions were calculated by dividing the response rate from each link during each pre-feeding session by the mean response rate from that link during the last six baseline sessions. The logarithm of that proportion then was graphed. The solid horizontal lines plotted at zero show the baseline level of responding in each component for each pigeon, such that any point below this line represents a decrease in response rates, relative to baseline, any point above this line represents an increase in response rates and any point on this line represents no change from baseline. The decrease in initial-link response rates in the Vary component was less than the decrease in response rates in the Repeat component during the last three sessions for Pigeon 12 and during the last five sessions for Pigeon 11. For Pigeon 14, initial-link response rates in the Vary component tended to be closer to baseline level, with the exception of the last session. The decrease in terminal-link response rates in the Vary component again was less than the decrease in response rates in the Repeat component during the last three sessions for Pigeon 12 and during the last five sessions for Pigeon 11. For Pigeon 14, there was no systematic change in terminal-link response rates in the two components. 


\section{Next Page}

Figure 3. Log proportion of baseline responses (left graphs) or response sequences (right graphs) per minute in the initial (left graphs) and terminal (right graphs) links of each component for each pigeon during each pre-feeding session. 


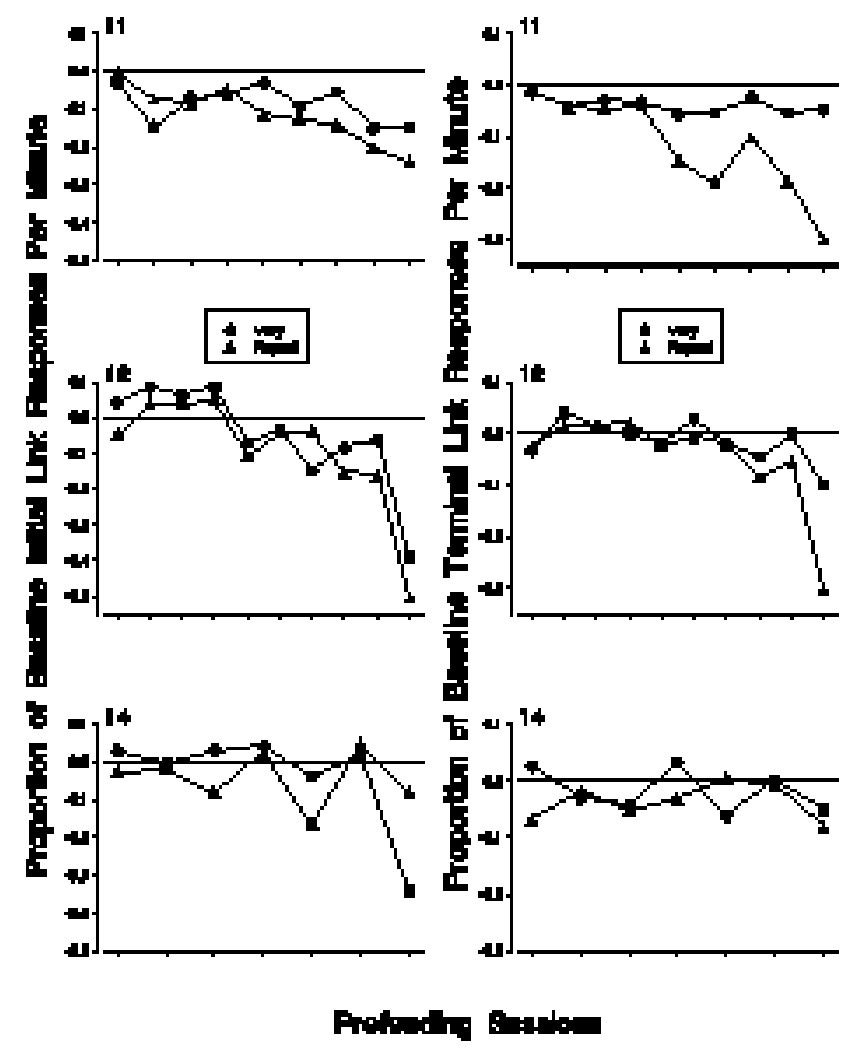


Figure 4 shows the relative frequency distributions during each component for the last five pre-feeding sessions for each pigeon. This figure was constructed as described above for Figure 2. The average U-values from these sessions also are shown in the middle of each panel. U-values in the Vary component decreased in all pigeons and in the Repeat component, only Pigeon 11 displayed a large U-value change. Two revealing features of this figure should be noted. First, the primary reason for the increase in Uvalue in the Repeat component for Pigeon 11 was the increase in the relative frequency of the response LLRL (the middle of the distribution). A second feature of this graph is the similarity in the distributions for Pigeons 14 and 11 in the Vary component. The relative frequency of the response sequences on the left side of the distribution (zero and one changeovers) greatly outnumber the relative frequency of the response sequences on the right side of the distribution (two and three changeovers). This effect was not obtained with Pigeon 12 but the most frequent response sequence for each pigeon during these sessions was LLLL.

Figure 5 shows, for each pigeon, the log proportion of baseline responses per minute in the initial (left three panels) and terminal links (right three panels) of each component during each VT 15-s schedule session, VT 5-s schedule sessions and VT 2.5-s schedule sessions. These proportions were calculated as described above for Figure 3. There are several noteworthy features in these figures. Larger decreases in initial-link response rates than terminal-link response rates were obtained and larger response-rate decreases during the earlier sessions of each VT-schedule than under the later sessions also were observed, although there are some counterinstances of the latter finding. Another general trend in the data at all three VT-values is that unequal decreases in response rates between the two components for each pigeon were obtained, with greater decreases in the Repeat component. This was true in both links for Pigeon 12 in every VT-schedule session except for the first VT 15-s schedule session. This also occurred in the initial link for Pigeon 14 in the first 2 VT 15-s schedule sessions, in the first and third VT 5-s schedule sessions and each VT 2.5-s schedule session. Each of these sessions, except for the final four under the VT 2.5-s schedule, also produced the same results as above for Pigeon 14 in the terminal link. For Pigeon 11, this effect was observed in the 


\section{Next Page}

Figure 4. Relative frequencies of each of the 16 possible response sequences obtained for each pigeon in each component during the last five pre-feeding sessions. Average Uvalues from these sessions also are shown in the middle of each panel. 

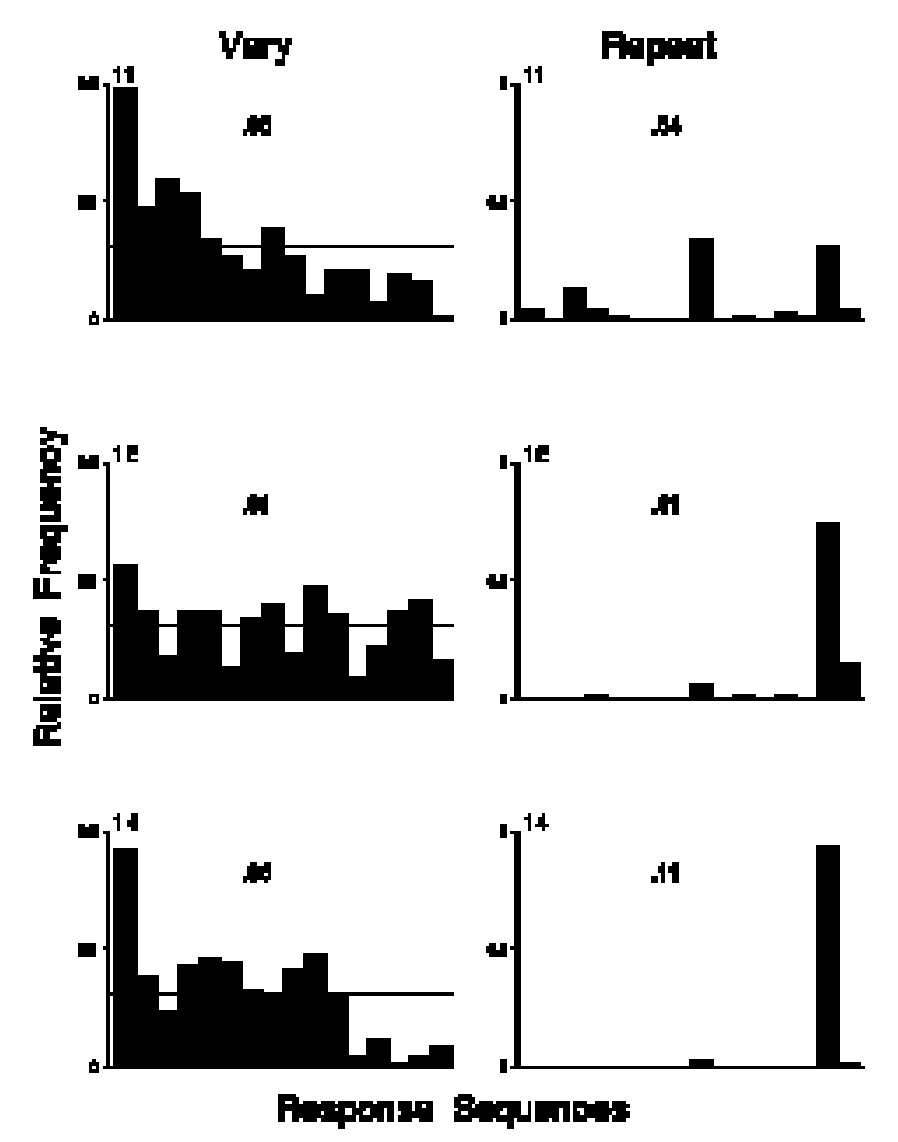


\section{Next Page}

Figure 5. Log proportion of baseline responses (left graphs) or response sequences (right graphs) per minute in the initial (left graphs) and terminal links (right graphs) of each component during each VT 15-s schedule session, VT 5-s schedule sessions and VT 2.5-s schedule sessions. 


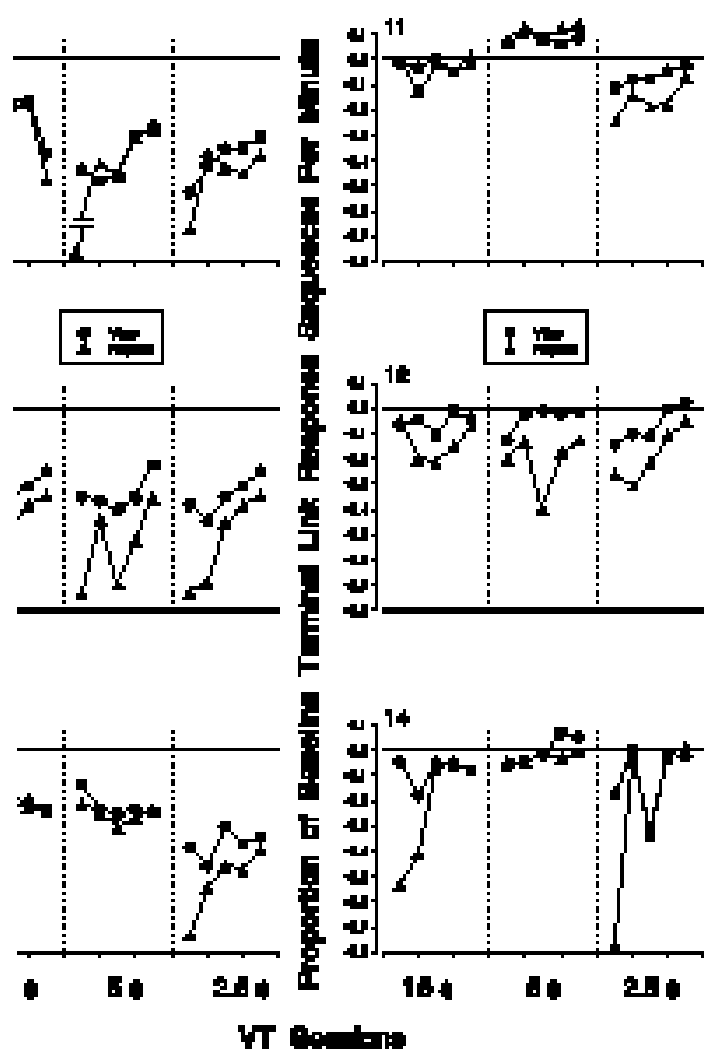


initial link under three VT 15-s schedule sessions, the first VT 5-s schedule session and four VT 2.5-s schedule sessions. This effect also was obtained in the terminal link for Pigeon 11 during the second VT 15-s schedule session and during each VT 2.5-s schedule session. During each of the sessions not mentioned above, the decrease in response rates was similar between the two components, except for the second VT 2.5-s schedule session for Pigeon 11, in which the decrease in response rates was greater in the Vary component.

Figure 6 shows the relative frequency distributions of response sequences during each component combined from each VT-schedule session for each pigeon. Figure 6 was constructed as described for Figures 2 and 4. The VT-schedule sessions were grouped together because there was little difference between each of these sessions, despite differences in their values (i.e., 15, 5, and $2.5 \mathrm{~s}$ ). The average U-values from these sessions also are shown in the middle of each panel. The decrease in U-values in the Vary component from the baseline sessions displayed in Figure 2 were less than the Uvalue increases obtained in the Repeat component. A second feature of this figure, and one which will be emphasized in greater detail below (see the discussion), is the change in the relative frequencies in the Vary component. Specifically, the relative frequencies of LRLR and RLRL (the rightmost two responses along the X-axis), increased considerably for each pigeon from the baseline sessions. 


\begin{abstract}
Next Page
Figure 6. Relative frequencies of each of the 16 possible response sequences combined from each VT-schedule session for each pigeon in each component. Average U-values from these sessions also are shown in the middle of each panel.
\end{abstract}



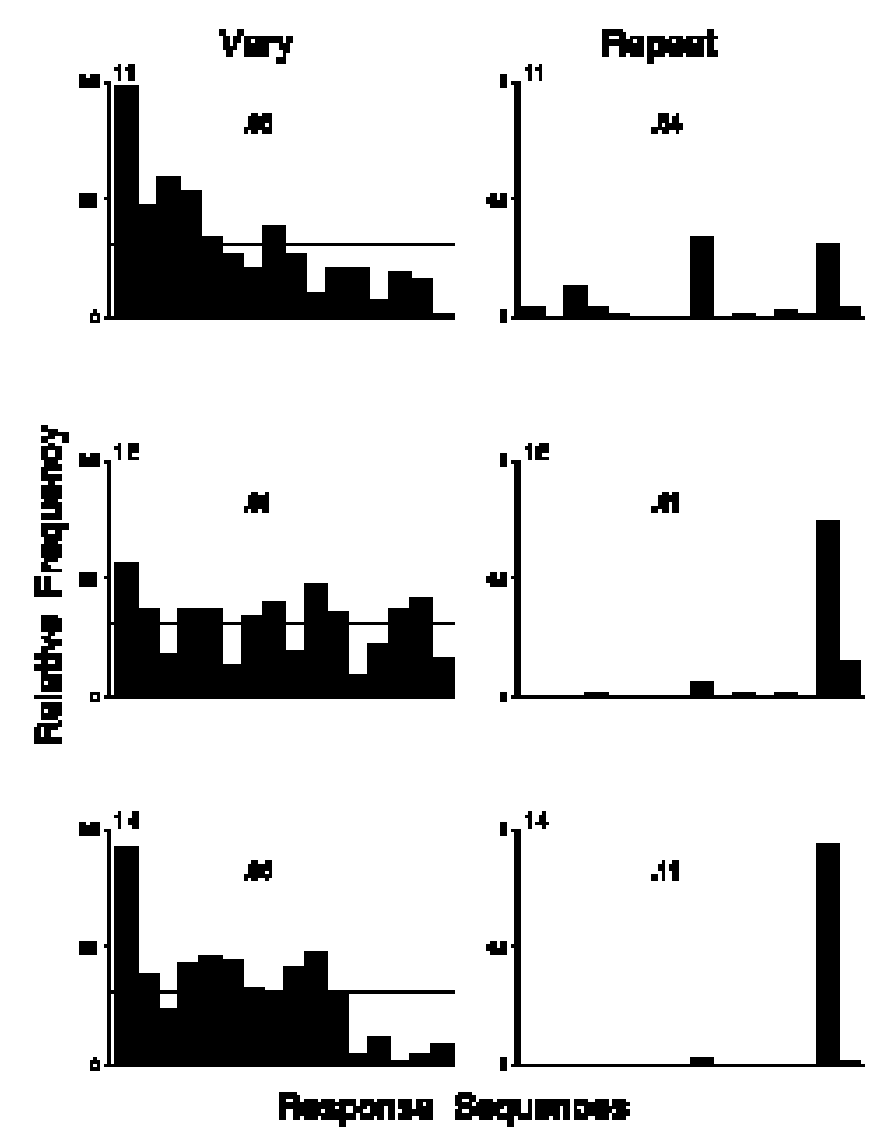
Chapter 3 - Conclusions

\section{Discussion}

Greater resistance to pre-feeding and response-independent food delivered during the inter-component intervals was obtained in the initial and terminal links during the component in which response variation was reinforced (Vary) than in the component during which only a single, fixed response sequence was reinforced (Repeat). This greater response persistence in the Vary Component was obtained despite similar response and reinforcement rates during each of the two terminal links and different types of changes in the relative frequencies of the 16 response sequences, during the Vary component, as a function of the two disrupting operations. These findings extend the observations of Neuringer (1991, 1999; see also, Cohen et al., 1990) and attest to the reliability and generality of the conclusion that, with similar reinforcement rates, response variation is stronger, or more resistant to environmental disruption, than response repetition.

The baseline levels of response variation and repetition obtained in the present experiment, as indexed by the U-values, replicate earlier findings demonstrating that response variation can be reinforced (e.g., Page \& Neuringer, 1985) and that response variation and repetition can be brought under discriminative stimulus control (e.g., Denney \& Neuringer, 1998). Although the present experiment was not conducted to determine whether such variation is reinforced directly (Page \& Neuringer, 1985) or through some other process (cf. Machado, 1997), aspects of the results reveal some of the characteristics of the response class labeled response variation. As such, these results may inform us on how to describe the properties of this response class. Related to such a description were the different changes observed in the relative frequencies of the 16 response sequences as a function of the two disrupters. During the pre-feeding sessions, the relative frequencies of the response sequences containing the higher number of changeovers decreased and the relative frequencies of the response sequences containing the lower number of changeovers increased, relative to baseline, while during the VTschedule sessions, the relative frequencies of LRLR and RLRL increased considerably, relative to baseline. This latter induction-like effect has been observed during baseline 
conditions (Cohen et al., 1990) but not following some manipulation. That such modification occurred as a function of the two disrupters has implications for the description of what constitutes a response class and/or an operant and this is especially relevant to the response class that has been labeled response variation. That is, although response variation is the functional response class, all topographies within that class are not equally affected by other manipulations. Thus, it might be beneficial, or even necessary, to consider the organization or structure of the constituent parts of particular response classes for a complete understanding of behavior (cf. Shimp, 1976).

The present findings also bear directly on interpretations of the concept response strength, particularly with respect to behavioral momentum theory (e.g., Nevin, 1992), in that some of the results both replicate earlier findings and present problems for a behavioral momentum approach to resistance to change. In each component, initial-link response rates decreased more, relative to their own baseline level, than terminal-link response rates. This finding replicates past research (Mellon \& Shull, 1986; Nevin et al., 1981) and is consistent with the interpretation that responding maintained by primary reinforcement is stronger, that is, more resistant to disruption, than is responding maintained by conditioned reinforcement and/or delayed primary reinforcement.

Describing the greater persistence of initial-link response rates in the Vary component is not as straightforward. Specifically, although terminal-link response and reinforcement rates were nearly identical throughout the baseline conditions, initial-link response rates were consistently lower in the Vary component. Because it is typically suggested that response rates in the initial link of a chained schedule represent the reinforcing efficacy of the terminal link, one might predict that responding to produce the Vary terminal link was less reinforcing than responding to produce the Repeat terminal link, even though the resistance-to-change results reliably showed that initial-link response rates were more persistent during the Vary component. A different interpretation of the lower initial-link response rates during the Vary component is suggested by the results of Lattal and Crawford-Godbey (1985), who compared initiallink key pecking in pigeons as a function of the type of response (key pecking or treadle pressing) required in the upcoming terminal link. Despite similar reinforcement rates 
arranged in each terminal link, key-peck response rates preceding the treadle-pressing terminal link were reliably lower than key-peck response rates in the initial link preceding the terminal link requiring key pecking. The authors concluded that, with reinforcement rate and delay equal, heterogeneous chains, in which two different response topographies are required in the two links, maintain lower initial-link response rates than homogeneous chains, in which the same response topography is required in each link. The lower response rates in the initial link preceding the Vary component in the present experiment may be described similarly. That is, initial-link responding was similar in the two components in that it was the repetition of center-key pecking, while response repetition (LRLR) also was required in the Repeat terminal link. In the Vary component during the terminal link, response repetition was not reinforced and indirectly punished (i.e., emitting the same response repeatedly decreased the probability of reinforcement), so perhaps the Vary component can be characterized as a heterogeneous chain and the Repeat component as a homogeneous chain. Under this interpretation, one would predict the lower response rates obtained during the initial link of the Vary component. Thus, that greater resistance-to-change was observed during the initial link of the Vary component, relative to the Repeat component, could be predicted by previous findings demonstrating that, with other things being equal, lower response rates are more persistent than higher response rates (Blackman, 1968; Lattal, 1989; but see Fath, Fields, Malott, \& Grossett, 1983).

The greater response persistence during the terminal link of the Vary component, relative to the Repeat terminal link, is more difficult to incorporate with earlier findings (e.g., Nevin, 1992) than was the initial-link differences described above. This is because behavioral momentum theory does not account for the present differential resistance to change as reinforcement rates were similar in the two components. These findings do, however, lend support to the suggestion that different response topographies can yield differential resistance to change (cf. Grace et al., 1998). Before describing how these different response topographies might yield differential resistance-to-change, however, consider an interpretation that is suggested by earlier research (e.g., Machado, 1997) and the present pre-feeding results. Perhaps the response sequence LRLR was more effortful 
because the pigeon had to changeover more and this increased effort produced less resistance to change. The fact that the relative frequencies of LRLR and RLRL decreased during the Vary component when the pigeons were pre-fed support this notion. A problem for this interpretation, however, is the increase in the relative frequencies of LRLR and RLRL in the Vary component during the VT-schedule conditions and that responding was more persistent during this disruption condition, relative to the Repeat component, as well.

Returning to the notion that different response topographies can yield differential resistance to change, a reason why a variable response class is stronger, or more resistant to disruption, than a repetitive one, relates to the constituent parts of a response class. In the Repeat component, LRLR was the only response sequence that was reinforced, thus it reached some asymptotic level of "strength" sometime during training, above which further reinforcement might have had little effect. In the Vary component, however, each of the 16 response sequences might have reached its own level of "strength" that, when summed together, might have surpassed that achieved by the response sequence LRLR (in the Repeat component). Thus, the disruption conditions somehow revealed this history such that the persistence of responding during the Vary component, with its several constituent parts, exceeded that during the Repeat component, with only its one part. Such an interpretation also may be used to describe the greater persistence obtained under DRL schedules, relative to ratio schedules (Lattal, 1989), in that under the former, multiple response classes are reinforced (e.g., key pecking and pausing), whereas under the latter, only a single response class (key pecking) is reinforced.

The above interpretation, emphasizing the role of the constituent parts of a response class, suggesting why response variation is stronger than response repetition could be corroborated by further resistance-to-change tests comparing the persistence of response classes consisting of different sizes (e.g., numbers of response sequences available for reinforcement). Related to such an interpretation, Neuringer, Olson, and Deiss (2000) recently demonstrated greater "adaptation”, or persistence, by response classes consisting of a greater number of response sequences (i.e., a varied response class) when reinforcement contingencies changed such that a new response sequence was 
now reinforced. The present research and the findings obtained by Neuringer et al. (2000) also have parallels in natural selection where variation is necessary for the selection and promotion of particular traits (e.g., Glenn \& Madden, 1995; Skinner, 1981). As Catania (1985) observed in describing these similarities between biological and ontogenetic selection, "Variability itself has consequences... just as ontogenetic shaping will proceed more slowly with stereotyped than with variable behavior, a population that has become relatively homogeneous in genotype as a result of extended exposure to a stable environment may be less likely to survive environmental disruptions than one that has become relatively heterogeneous in changing environments" (p. 477). The present findings suggest that a response class that has become relatively homogeneous in topography may be less likely to survive, or persist, when environmental disruptions occur than one that is relatively heterogeneous. 


\section{References}

Antonitis, J. J. (1951). Response variability in the white rat during conditioning, extinction, and reconditioning. Journal of Experimental Psychology, 42, 273-281.

Arbuckle, J. L., \& Lattal, K. A. (1988). Changes in functional response units with briefly delayed reinforcement. Journal of the Experimental Analysis of Behavior, 49, 249-263.

Bell, M. C. (1999). Pavlovian contingencies and resistance to change in a multiple schedule. Journal of the Experimental Analysis of Behavior, 72, 81-96.

Blackman, D. (1968). Response rate, reinforcement frequency, and conditioned suppression. Journal of the Experimental Analysis of Behavior, 11, 503-516.

Blough, D. S. (1966). The reinforcement of least-frequent interresponse times. Journal of the Experimental Analysis of Behavior, 9, 581-591.

Brown, P. L., \& Jenkins, H. M. (1968). Auto-shaping of the pigeon's key-peck. Journal of the Experimental Analysis of Behavior, 11, 1-8.

Bryant, D., \& Church, R. M. (1974). The determinants of random choice. Animal Learning and Behavior, 2, 245-248.

Catania, A. C. (1985). Problems of selection and phylogeny, terms and methods of behaviorism. In A. C. Catania \& S. Harnad (Eds.), The selection of behavior. New York, NY: Cambridge University Press.

Cohen, L., Neuringer, A., \& Rhodes, D. (1990). Effects of ethanol on reinforced variations and repetitions by rats under a multiple schedule. Journal of the Experimental Analysis of Behavior, 54, 1-12.

Denney, J. \& Neuringer, A. (1998). Behavioral variability is controlled by discriminative stimuli. Animal Learning and Behavior, 26, 154-162.

Fath, S. J., Fields, L., Malott, M. K., \& Grossett, D. (1983). Response rate, latency, and resistance to change. Journal of the Experimental Analysis of Behavior, 39, 267-274.

Ferster, C. B., \& Skinner, B. F. (1957). Schedules of reinforcement. New York: Appleton-Century-Crofts.

Fleshler, M., \& Hoffman, H. S. (1962). A progression for generating variable-interval schedules. Journal of the Experimental Analysis of Behavior, 5, 529-530. 
Freeman, T. J., \& Lattal, K. A. (1992). Stimulus control of behavioral history. Journal of the Experimental Analysis of Behavior, 57, 5-15.

Grace, R. C., Schwendiman, J. W., \& Nevin, J. A. (1998). Effects of unsignaled delay of reinforcement on preference and resistance to change. Journal of the Experimental Analysis of Behavior, 69, 247-261.

Glenn, S., \& Madden, G. (1995). Units of interaction, evolution, and replication: Organic and behavioral parallels. The Behavior Analyst, 18, 237-251.

Holman, J., Goetz, E. M., \& Baer, D. M. (1977). The training of creativity as an operant and an examination of its generalization characteristics. In B. C. Etzel, J. M. LeBlanc, \& D. M. Baer (Eds.), New developments in behavioral research: Theory, method, and application (pp. 441-471). Hillsdale, N. J.: Lawrence Erlbaum Associates.

Hunziker, M. H. L., Saldana, L., \& Neuringer, A. (1996). Behavioral variability in SHR and WKY rats as a function of rearing environment and reinforcement contingency. Journal of the Experimental Analysis of Behavior, 65, 129-144.

Joyce, J. H., \& Chase, P. N. (1990). Effects of response variability on the sensitivity of rule-governed behavior. Journal of the Experimental Analysis of Behavior, 54, 251-262.

Kramer, T. J., \& Rilling, M. (1970). Differential reinforcement of low rate: A selective critique. Psychological Bulletin, 74, 225-254.

Lattal, K. A. (1974). Combinations of response-reinforcer dependence and independence. Journal of the Experimental Analysis of Behavior, 22, 357-362.

Lattal, K. A. (1989). Contingencies on response rate and resistance to change. Learning and Motivation, 20, 191-203.

Lattal, K. A., \& Crawford-Godbey, C. L. (1985). Homogeneous chains, heterogeneous chains, and delay of reinforcement. Journal of the Experimental Analysis of Behavior, 44, 337-342.

MacCorquodale, K. \& Meehl, P. E. (1948). On a distinction between hypothetical constructs and intervening variables. Psychological Review, 55, 95-107. 
Mace, F. C., Lalli, J. S., Shea, M. C., Lalli, E. P., West, B. J., Roberts, M., \& Nevin, J. A. (1990). The momentum of human behavior in a natural setting. Journal of the Experimental Analysis of Behavior, 54, 163-172.

Machado, A. (1989). Operant conditioning of behavioral variability using a percentile reinforcement schedule. Journal of the Experimental Analysis of Behavior, 52 , 155-166.

Machado, A. (1992). Behavioral variability and frequency-dependent selection. Journal of the Experimental Analysis of Behavior, 58, 241-263.

Machado, A. (1993). Learning variable and stereotypical sequences of responses: Some data and a new model. Behavioural Processes, 30, 103-130.

Machado, A. (1997). Increasing the variability of response sequences in pigeons by adjusting the frequency of switching between two keys. Journal of the Experimental Analysis of Behavior, 68, 1-25.

Marguiles, S. (1961). Response duration in operant level, regular reinforcement, and extinction. Journal of the Experimental Analysis of Behavior, 4, 317-321.

Mellon, R. C., \& Shull, R. L. (1986). Resistance to change produced by access to fixeddelay versus variable-delay terminal links. Journal of the Experimental Analysis of Behavior, 46, 79-92.

Miller, G. A., \& Frick, F. C. (1949). Statistical behavioristics and sequences of responses. Psychological Review, 56, 311-324.

Morris, C. J. (1987). The operant conditioning of response variability: Free-operant versus discrete-response procedures. Journal of the Experimental Analysis of Behavior, 47, 273-277.

Neuringer, A. (1992). Choosing to vary and repeat. Psychological Science, 3, 246-250.

Neuringer, A. (1993). Reinforced variation and selection. Animal Learning and Behavior, 21, 83-91.

Neuringer, A., Olson, G., \& Deiss, C. (2000). Reinforced variability and operant learning. Journal of Experimental Psychology: Animal Behavior Processes, 26(1), 98-111. 
Nevin, J. A. (1974). Response strength in multiple schedules. Journal of the Experimental Analysis of Behavior, 21, 389-408.

Nevin, J. A. (1979). Reinforcement schedules and response strength. In M. D. Zeiler \& P. Harzem (Eds.), Advances in analysis of behavior: (Vol. 1). Reinforcement and the organization of behavior (pp. 117-158). Chichester, England: Wiley.

Nevin, J. A. (1984). Pavlovian determiners of behavioral momentum. Animal Learning and Behavior, 12, 363-370.

Nevin, J. A. (1988). Behavioral momentum and the partial reinforcement effect. Psychological Bulletin, 103, 44-56.

Nevin, J. A. (1992). An integrative model for the study of behavioral momentum. Journal of the Experimental Analysis of Behavior, 57, 301-316.

Nevin, J. A. (1995). Behavioral economics and behavioral momentum. Journal of the Experimental Analysis of Behavior, 64, 385-395.

Nevin, J. A., Mandell, C., \& Atak, J. R. (1983). The analysis of behavioral momentum. Journal of the Experimental Analysis of Behavior, 39, 49-59.

Nevin, J. A., Mandell, C., \& Yarensky, P. (1981). Response rate and resistance to change in chained schedules. Journal of Experimental Psychology: Animal Behavior Processes, 7, 278-294.

Nevin, J. A., Smith, L. D., \& Roberts, J. (1987). Does contingent reinforcement strengthen operant behavior? Journal of the Experimental Analysis of Behavior, 48 , $17-33$.

Nevin, J. A., Tota, M. E., Torquato, R. D., \& Shull, R. L. (1990). Alternative reinforcement increases resistance to change: Pavlovian or operant contingencies? Journal of the Experimental Analysis of Behavior, 53, 359-379.

Notterman, J. M., \& Mintz, P. E. (1965). Dynamics of response. New York: Willey. Page, S., \& Neuringer, A. (1985). Variability is an operant. Journal of Experimental Psychology: Animal Behavior Processes, 11, 429-452.

Pryor, K. W., Haag, R., \& O'Reilly, J. (1969). The creative porpoise: Training for novel behavior. Journal of the Experimental Analysis of Behavior, 12, 653-661. 
Schaal, D. W., Shahan, T. A., Kovera, C. A., \& Reilly, M. P. (1998). Mechanisms underlying the effects of unsignaled delayed reinforcement on key pecking of pigeons under variable-interval schedules. Journal of the Experimental Analysis of Behavior, 169, 103-122.

Schwartz, B. (1980). Development of complex, stereotyped behavior in pigeons. Journal of the Experimental Analysis of Behavior, 33, 153-166.

Schwartz, B. (1982a). Failure to produce response variability with reinforcement. Journal of the Experimental Analysis of Behavior, 37, 171-181.

Schwartz, B. (1982b). Interval and ratio reinforcement of a complex sequential operant in pigeons. Journal of the Experimental Analysis of Behavior, 37, 349-357.

Schwartz, B. (1982c). Reinforcement creates behavioral units. Behavior Analysis Letters, 1, 33-41.

Shimp, C. P. (1967). Reinforcement of least-frequent sequences of choices. Journal of the Experimental Analysis of Behavior, 10, 57-65.

Shimp, C. P. (1976). Organization in memory and behavior. Journal of the Experimental Analysis of Behavior, 26, 113-130.

Sidman, M. (1960). Tactics of scientific research: Evaluating experimental data in psychology. New York: Basic Books.

Skinner, B. F. (1938). Behavior of organisms: An experimental analysis. New York: Appleton-Century.

Skinner, B. F. (1948). "Superstition" in the pigeon. Journal of Experimental Psychology, 38, 168-172.

Skinner, B. F. (1966). An operant analysis of problem solving. Contingencies of reinforcement. New York: Appleton-Century-Crofts.

Skinner, B. F. (1981). Selection by consequences. Science, 213, 501-504.

Staddon, J. E. R., \& Simmelhag, V. L. (1971). The "superstition" experiment: A reexamination of its implications for the principles of adaptive behavior.

Psychological Review, 78, 3-43.

Starin, S. (1989). Choice and terminal-link response topography. Journal of the Experimental Analysis of Behavior, 51, 243-257. 
Timberlake, W., \& Lucas, G. A. (1985). The basis of superstitious behavior: Chance contingency, stimulus substitution, or appetitive behavior? Journal of the Experimental Analysis of Behavior, 44, 279-299.

Vogel, R., \& Annau, Z. (1973). An operant discrimination task allowing variability of reinforced response patterning. Journal of the Experimental Analysis of Behavior, 20, $1-6$.

Winston, A. S. \& Baker, J. E. (1985). Behavior analytic studies of creativity: A critical review. The Behavior Analyst, 8, 191-205. 